\title{
Integrated Systems Design of a Cargo Aircraft with Environmentally Responsible Goals
}

\author{
Eric M. Boekeloo ${ }^{1}$ \\ University of Michigan, Ann Arbor, MI, 48109 \\ Anthony J. Favaloro ${ }^{2}$ \\ Mississippi State University, Mississippi State, MS, 39762 \\ Timothy C. Harris ${ }^{3}$ \\ Purdue University, West Lafayette, IN, 47907 \\ Luke J. Humphrey ${ }^{4}$ \\ Montana State University, Bozeman, MT, 59717 \\ Brandon J. Johnson ${ }^{5}$ \\ Stanford University, Stanford, CA, 94305 \\ Troy E. Lake, Jr. ${ }^{6}$ \\ Wichita State University, Wichita, KS, 67260 \\ Collin A. McAtee ${ }^{7}$ \\ Auburn University, Auburn, AL, 36849 \\ Kimberly S. Scheider ${ }^{8}$ \\ Old Dominion University, Norfolk, VA, 23508 \\ Yukiko S. Shimizu ${ }^{9}$ \\ Massachusetts Institute of Technology, Cambridge, MA, 02139 \\ and \\ Barrett B. Tirey ${ }^{10}$ \\ University of Kentucky, Lexington, $K Y, 40506$
}

\footnotetext{
${ }^{1}$ Graduate Student, Aerospace Engineering, 1011 North University Ave, Ann Arbor, MI 48109, Student Member.

${ }^{2}$ Undergraduate Student, Aerospace Engineering, 330 Walker at Hardy Rd, Mississippi State, MS 39762, Student Member.

${ }^{3}$ Undergraduate Student, Aeronautical Engineering, 475 Stadium Mall Dr., West Lafayette, IN 47907, Student Member.

${ }^{4}$ Undergraduate Student, Mechanical Engineering, P.O. Box 172190, Bozeman, MT 59717, Student Member.

${ }^{5}$ Graduate Student, Aeronautical Engineering, 496 Lomita Mall, Stanford, CA 94305, Student Member.

${ }^{6}$ Undergraduate Student, Aerospace Engineering, 1845 N Fairmount, Wichita, KS 67260, Student Member.

${ }^{7}$ Undergraduate Student, Aerospace Engineering, 211 Aerospace Engineering Building, Auburn, AL 36849, Student Member.

${ }^{8}$ Undergraduate Student, Mechanical Engineering, 5115 Hampton Boulevard, Norfolk, VA 23508, Non-Member.

${ }^{9}$ Undergraduate Student, Aerospace Engineering, 77 Massachusetts Avenue, Cambridge, MA 02139, Student Member.

${ }^{10}$ Undergraduate Student, Mechanical Engineering, 351 Ralph G. Anderson Building, Lexington, KY 40506, NonMember.
} 
The Aeronautics Academy at NASA Langley Research Center investigated conventional and unconventional designs for a next generation cargo aircraft and compared them to a current, state of the art baseline. Aircraft concepts were evaluated based on N+2 ERA goals. The feasibility of implementing the concepts as unmanned systems was also investigated. System level studies identified hybrid wing body, truss-braced wing, and multiple fuselage configurations as potentially beneficial in reducing fuel burn, emissions and perceived noise. Each concept incorporated future technologies in aerodynamics, propulsion, structures, and materials in order to maximize fuel burn and perceived noise reductions.

\section{Nomenclature}

\begin{tabular}{|c|c|c|}
\hline$A C C A$ & $=$ & Advanced Composite Cargo Aircraft \\
\hline$A P U$ & $=$ & Auxiliary Power Unit \\
\hline$A R M D$ & $=$ & Aeronautics Research Mission Directorate \\
\hline$B F G S$ & $=$ & Broyden-Fletcher-Goldfarb-Shano \\
\hline Bio-SPK & $=$ & Bio Synthetic Paraffin Kerosene \\
\hline$B L I$ & $=$ & Boundary Layer Ingestion \\
\hline$C A E P$ & $=$ & Committee on Aviation Environmental Protection \\
\hline C.G. & $=$ & Center of Gravity \\
\hline $\mathrm{CO}_{2}$ & $=$ & Carbon Dioxide \\
\hline$C T W$ & $=$ & Conventional Tube and Wing \\
\hline$d B$ & $=$ & Decibel \\
\hline$E B F 3$ & $=$ & Electron Beam Free Form Fabrication \\
\hline$E F W$ & $=$ & Extruded Flying Wing \\
\hline$E P A$ & $=$ & Environmental Protection Agency \\
\hline EPNL & $=$ & Effective Perceived Noise Level \\
\hline$E R A$ & $=$ & Environmentally Responsible Aviation \\
\hline$F A A$ & $=$ & Federal Aviation Administration \\
\hline FLOPS & $=$ & Flight Optimization System \\
\hline$G E$ & $=$ & General Electric \\
\hline$G R C$ & $=$ & NASA Glenn Research Center \\
\hline$G T F$ & $=$ & Geared Turbo Fan \\
\hline$H L F C$ & $=$ & Hybrid Laminar Flow Control \\
\hline$H W B$ & $=$ & Hybrid Wing Body \\
\hline LaRC & $=$ & NASA Langley Research Center \\
\hline LTO & $=$ & Landing and Takeoff \\
\hline MTOW & $=$ & Maximum Takeoff Weight \\
\hline$N A C A$ & $=$ & National Advisory Committee for Aeronautics \\
\hline$N A S$ & $=$ & National Airspace System \\
\hline NASA & $=$ & National Aeronautics and Space Administration \\
\hline$N O_{X}$ & $=$ & Oxides of Nitrogen \\
\hline$O O A$ & $=$ & Out Of Autoclave \\
\hline PRSEUS & $=$ & Pultruded Rod Stitched Efficient Unitized Structure \\
\hline$P W$ & $=$ & Pratt and Whitney \\
\hline$S M A$ & $=$ & Shape Memory Alloys \\
\hline SOFC & $=$ & Solid Oxide Fuel Cell \\
\hline$T B W$ & $=$ & Truss-Braced Wing \\
\hline$T R L$ & $=$ & Technology Readiness Level \\
\hline$U A S$ & $=$ & Unmanned Aircraft Systems \\
\hline$U D F$ & $=$ & Unducted Fan \\
\hline$V S P$ & $=$ & Vehicle Sketch Pad \\
\hline
\end{tabular}




\section{Introduction}

$I$ N response to goals set forth by NASA's Environmentally Responsible Aviation (ERA) project, the 2011

Aeronautics Academy, at NASA's Langley Research Center (LaRC), investigated emerging technologies and novel aircraft configurations applicable to the development of next generation cargo aircraft. The ERA N+2 (2025 timeframe) goals reflect an increasing awareness of the need to reduce greenhouse gas emissions, limit air and noise pollution, and reduce operator costs. The aim of the ERA goals is achieved by reducing carbon dioxide $\left(\mathrm{CO}_{2}\right)$ emissions, limiting nitrogen oxide $\left(\mathrm{NO}_{\mathrm{x}}\right)$ and noise emissions, and reducing fuel burn, respectively.

In parallel with efforts to mitigate the environmental impact of aviation are efforts to more efficiently utilize the National Airspace System (NAS). Noise reductions and the use of unmanned aircraft systems (UAS) have the potential to do both. Reducing aircraft noise signatures will permit greater utilization of existing airport infrastructure, such as late night operations, while minimizing the impact on surrounding areas. Implementation of UAS has the potential to maximize the use of the NAS. The importance of the ERA goals is underlined by the projected growth in air travel and air transportation; the total number of aircraft in the fleet is projected to triple by $2050 .^{1}$

At the same time, the utility of any new aircraft concept remains paramount. Thus, the concepts analyzed in this study adhered to given requirements regarding speed, range, and payload. This report discusses the design process used to find and analyze both a conventional tube and wing design (CTW) and two novel configurations for a next generation, cargo-specific, long-haul aircraft.

\section{Conceptual Design and Selection}

\section{A. Conceptual Design Methodology}

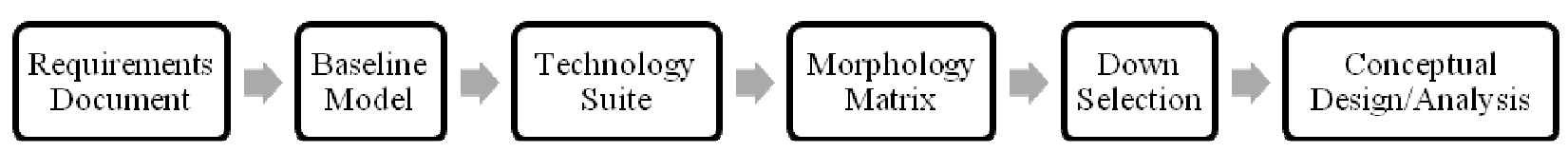

Figure 1. Conceptual Design Process

The design process, outlined in Figure 1, began with the creation of a requirements document based on both the ERA N+2 goals, shown in Table 1, and mission requirements. Both the CTW and unconventional designs were required to carry 100,000 pounds of cargo, travel 6,500 nautical miles, and cruise at approximately Mach 0.85 . The feasibility of removing the pilots from the aircraft was considered as part of the UAS in the NAS Project. Derived requirements for field length, maximum takeoff weight (MTOW), approach speed, time to climb, and various other parameters were determined.

Table 1. NASA Subsonic Transport System Level Metrics ${ }^{2}$

\begin{tabular}{|c|c|c|c|}
\hline \multirow[b]{2}{*}{$\begin{array}{l}\text { TECHNOLOGY } \\
\text { BENEFITS* }\end{array}$} & \multicolumn{3}{|c|}{$\begin{array}{l}\text { TECHNOLOGY GENERATIONS } \\
\text { (Technology Readiness Level }=4-6 \text { ) }\end{array}$} \\
\hline & $\mathrm{N}+1(2015)$ & $\mathrm{N}+2\left(2020^{\star \star}\right)$ & $\mathrm{N}+3(2025)$ \\
\hline $\begin{array}{c}\text { Noise } \\
\text { (cum below Stage 4) }\end{array}$ & $-32 d B$ & $-42 d B$ & $-71 d B$ \\
\hline $\begin{array}{l}\text { LTO NOx Emissions } \\
\text { (below CAEP 6) }\end{array}$ & $-60 \%$ & $-75 \%$ & $-80 \%$ \\
\hline $\begin{array}{l}\text { Cruise NOx Emissions } \\
\text { (rel. to } 2005 \text { best in class) }\end{array}$ & $-55 \%$ & $-70 \%$ & $-80 \%$ \\
\hline $\begin{array}{l}\text { Aircraft Fuel/Energy Consumption }{ }^{\ddagger} \\
\text { (rel. to } 2005 \text { best in class) }\end{array}$ & $-33 \%$ & $-50 \%$ & $-60 \%$ \\
\hline
\end{tabular}

The baseline was created by identifying various aircraft currently flying similar missions, such as variations of the Boeing 767, Boeing 777, and Airbus 330. Due to the range capabilities, and the availability of an analysis model 
for NASA's Flight Optimization System (FLOPS), a Boeing 767 type aircraft was chosen. The FLOPS model was modified to reflect a cargo aircraft configuration and analyzed for the given mission profile. The benefits and disadvantages of the 767-based baseline were characterized to aid in identifying comparative advantages of novel configurations and the application of advanced technologies.

Once the baseline was solidified, a technology suite was developed (See Table 2). Team members surveyed advanced technologies from one of four functional areas: propulsion, airframe, aerodynamics, and systems. Advanced technologies were listed, along with their estimated benefit to ERA N+2 goals, and current Technology Readiness Level (TRL). In order to limit the design space to technologies likely to be available in the N+2 timeframe, advanced technologies with a TRL of less than 4 were not analyzed and are not discussed in detail.

A morphology matrix (See Table 3), containing all of the technologies, was created and used to formulate a set of conceptual designs (See Figure 2). A rough mission analysis was performed, for each concept, after updating the concept's FLOPS profile with weight and fuel savings estimates based on the morphological matrix.

The various advanced concepts were funneled through a down-selection process, governed by both limitations in FLOPS's analysis capabilities and design performance. Due to FLOPS's limitations, some unconventional designs could not be fully analyzed, and were therefore not considered further. Other designs were eliminated due to noncompetitive gross weight, fuel consumption, and thrust.

After down-selection, a detailed conceptual design and analysis of the three chosen designs was performed. Analysis included aircraft stability, aeroelastic considerations, noise, $\mathrm{NO}_{\mathrm{X}}$ emissions, fuel burn and $\mathrm{CO}_{2}$ emissions, cost, size, LTO, profile mission road maps, and UAS.

\section{B. Configurations Considered}

Configuration selection defines and has the potential to limit the scope of many aspects of a design. To avoid limiting configuration possibilities, new and unusual architectures were particularly emphasized (See Figure 2).
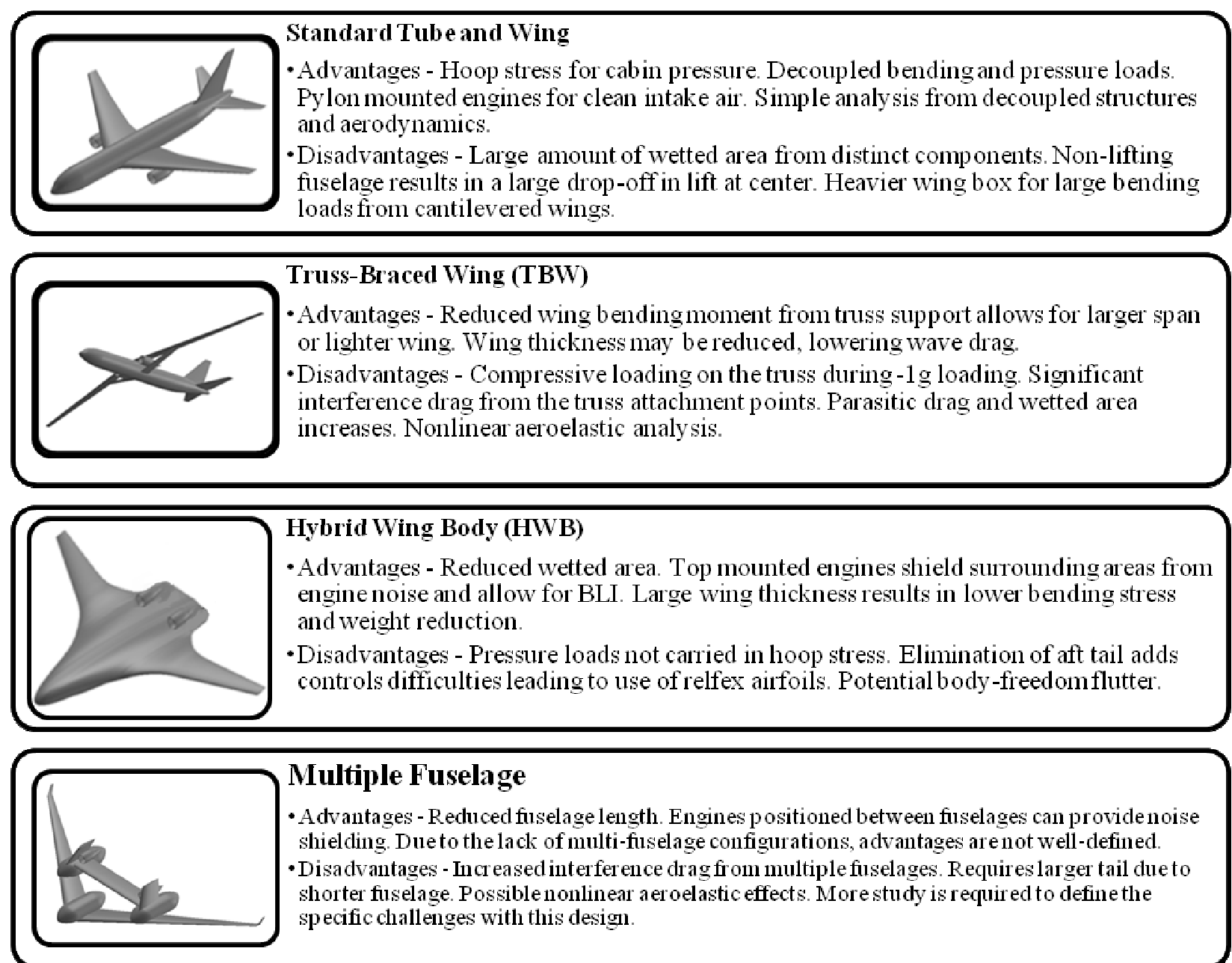

4

American Institute of Aeronautics and Astronautics 
-Advantages - The tip mounted C-wing acts as both a tail and a wingtip. Possible reduction in induced drag.

-Disadvantages - Additional structure for C-wing tips. Additional structure for highly swept wings. Wingtip movement during flight which could make tail control difficult.
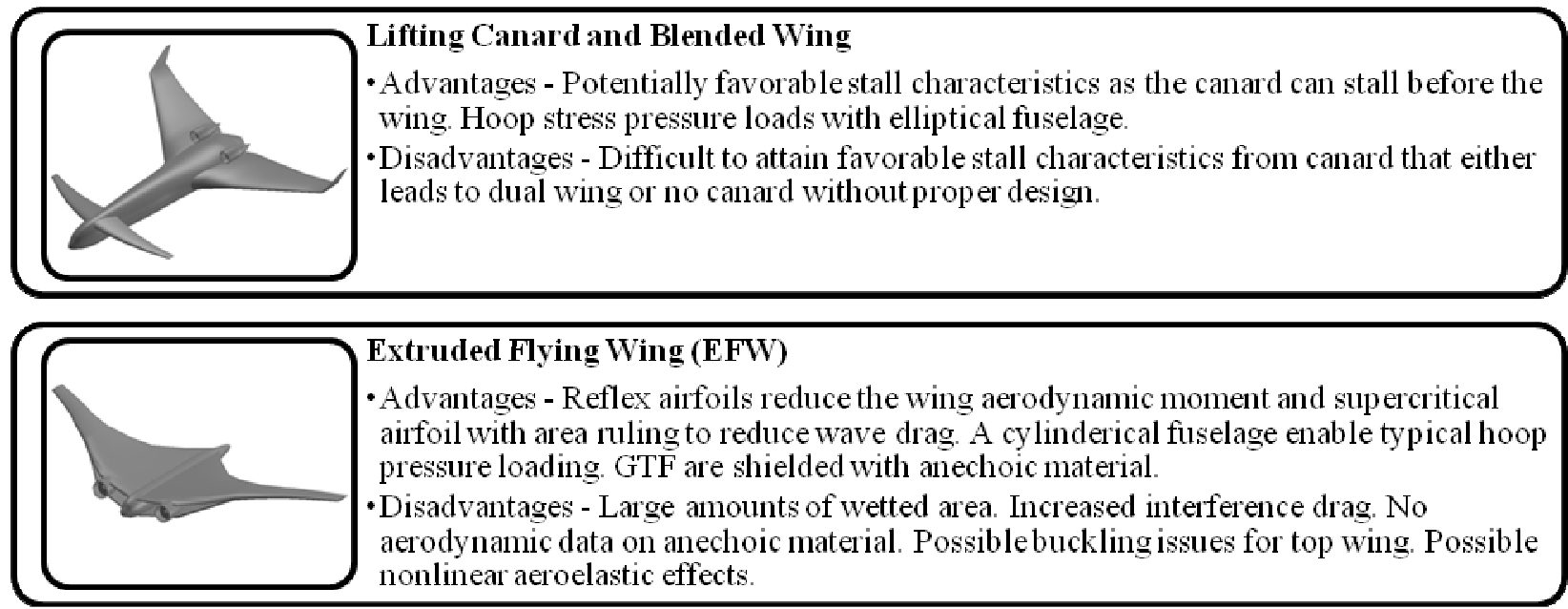

Figure 2. Concepts Considered.

\section{Advanced Technology Suite}

To meet the ERA project goals, advanced technologies, as well as novel configurations were considered. A suite of technologies likely to be available for implementation in the N+2 timeframe was assembled (See Table 2).

Table 2. Advanced Technology Suite

\begin{tabular}{|c|c|}
\hline Technology & Summary \\
\hline \multicolumn{2}{|l|}{ Aerodynamics } \\
\hline Riblets & $\begin{array}{l}\text { - Small bumps to reduce turbulent drag } \\
\text { - Shows potential for } 1-2 \% \text { total drag reduction } \\
\text { - Paint roller application leads to minimal maintenance costs } \\
\end{array}$ \\
\hline Laminar Flow Control (LFC) & $\begin{array}{l}\text { - Improves laminar flow over surface by suction } \\
\text { - Local drag reduction of } 20-30 \%{ }^{4} \\
\text { - Extra weight from system and associated sub-systems } \\
\end{array}$ \\
\hline Airfoils & $\begin{array}{l}\text { - Supercritical airfoils to reduce wave drag at high transonic Mach numbers } \\
\text { - Reflex airfoils to improve control an stability on tailless aircraft }\end{array}$ \\
\hline \multicolumn{2}{|l|}{ Propulsion } \\
\hline Open Rotor & $\begin{array}{l}\text { - Mitigates swirl losses and provides propulsive efficiency around } 95 \%{ }^{5} \\
\text { - Higher efficiency yields } 36 \% \text { reduction of fuel burn, based on a Boeing } 737 \text { - } \\
\text { - Wize aircraft } \\
\text { - With a lack of nacelle, the noise reduction is } 12 \mathrm{~dB} \text { less than that of a geared } \\
\text { turbofan, based on a Boeing } 737 \text {-size aircraft } \\
\text { - Rotor blades are speed limited to approximately Mach } 0.75^{7}\end{array}$ \\
\hline Geared Turbofan (GTF) & $\begin{array}{l}\text { - Gearbox allows fan to operate slower than booster for higher efficiency } \\
\text { - Increased weight from higher bypass ratio fans and the gearbox are mostly } \\
\text { mitigated by the fewer stages required in the booster }\end{array}$ \\
\hline Exhaust Chevrons & $\begin{array}{l}\text { - Exhaust noise reduced by mixing core, bypass, and ambient flow } \\
\text { - Can reduce core noise by } 3 \mathrm{~dB} \text { with a } 0.25 \% \text { fuel burn penalty }\end{array}$ \\
\hline
\end{tabular}




\begin{tabular}{|c|c|}
\hline $\begin{array}{l}\text { Boundary Layer Ingestion } \\
\text { (BLI) }\end{array}$ & $\begin{array}{l}\text { - Integration of propulsion systems into airframes and use of BLI may enable a } \\
10 \% \text { gain in efficiency for a blended wing body }{ }^{10} \\
\text { - Flow non-uniformity and pressure loss can cause loss in efficiency, increased } \\
\text { engine fatigue and noise } \mathrm{e}^{10,11} \\
\text { - Control of non-uniformity has been demonstrated to acceptable levels }{ }^{12}\end{array}$ \\
\hline Bio-derived Alternative Fuels & $\begin{array}{l}\text { - Drop-in replacements despite more processing, show similar performance to } \\
\text { traditional jet fuel }{ }^{13} \\
\text { - Poorer lubrication properties may require additives }{ }^{14} \\
\text { - Predicted to reduce well-to-wake greenhouse gasses at least } 50 \%{ }^{13,14} \\
\end{array}$ \\
\hline \multicolumn{2}{|r|}{ ( } \\
\hline $\begin{array}{l}\text { Out-of-Autoclave } \\
\text { Manufacturing (OOA) }\end{array}$ & $\begin{array}{l}\text { - X-55 seamless fuselage resulted in a 90\% reduction in the quantity of fasteners } \\
\text { and metallic parts }{ }^{15} \\
\text { - Reduction in parts can yield up to } 15-20 \% \text { structural weight savings }{ }^{16}\end{array}$ \\
\hline $\begin{array}{l}\text { Pultruded Rod Stitched } \\
\text { Efficient } \\
\text { Unitized Structure (PRSEUS) }\end{array}$ & $\begin{array}{l}\text { - Reinforced stitched carbon fiber skin with ribs and stiffeners in grid pattern } \\
\text { - Supports higher bending loads than a comparable weight of aluminum } \\
\text { - Allows for structural components such as the pressurized fuselage of the } \\
\text { blended wing bod }\end{array}$ \\
\hline
\end{tabular}

\section{Morphology Matrix}

The morphology matrix is a graphical tool that groups technologies together by function, allowing easier visualization and ensuring that possible technologies, and technology combinations, are not overlooked ${ }^{3,4}$.

Table 3. Morphology Matrix Example

\begin{tabular}{|c|c|c|c|c|}
\hline \multicolumn{2}{|c|}{ Characteristic } & \multicolumn{3}{c|}{ Options } \\
\hline \multirow{4}{*}{ Airframe } & Type & Tube \& Wing & Hybrid Wing Body & Joined Wing \\
\cline { 2 - 5 } & Wing Location & High & Mid & Low \\
\cline { 2 - 5 } & Wing Sweep & Aft Sweep & No Sweep & Forward Sweep \\
\cline { 2 - 5 } & Horizontal Stabilizer & V-Tail & Conventional & T-Tail \\
\hline \multirow{3}{*}{ Propulsion } & Type & Rotor Fan & Hybrid Turbo Electric & All-Electric \\
\cline { 2 - 5 } & Fuel & Liquid Hydrogen & JP-8 & Bio-fuel \\
\cline { 2 - 5 } & \# of Engines & 1 & 2 & 3 \\
\hline
\end{tabular}

Using Table 3, team members generated a first round of aircraft concepts. However, after a review of concepts by subject matter experts, it was decided that the concept aircraft were missing a truly unconventional design to help set this work apart from earlier studies. New concepts were generated with more emphasis placed on creating novel configurations.

\section{E. Down-selection}

After populating the morphology matrix from the advanced technology suite and configurations, technology combinations which conflicted, such as boundary layer ingestion with open rotor engines, were eliminated. The benefits and drawbacks of each conceptual design were estimated using FLOPS. Not all concepts were amenable to analysis using FLOPS, and these concepts were not studied further.

The metric for first round down-selection was based on gross weight, required fuel, and, to a lesser extent, thrust. Gross weight is typically proportional to direct operating cost and required fuel can be related to fuel burn for a given mission with similar engines.

The truss-based wing, HWB, and multi-fuselage concepts emerged as the most promising concepts. The preliminary analysis is shown in 
Table 4. Down-selection Matrix Similar N+2 technologies were assumed for all the configurations analyzed to provide aerodynamic, structural, and propulsive benefits, with the exception of the HWB, which uniquely utilized BLI. 
Table 4. Down-selection Matrix

\begin{tabular}{|c|c|c|c|c|c|c|c|}
\hline Configuration & Baseline & \multicolumn{2}{|c|}{ Canard } & \multicolumn{2}{c|}{ HWB } & \multicolumn{2}{c|}{ MultiFuse } \\
\hline Gross Weight & 587419 & 416620 & $29.08 \%$ & 376444 & $35.92 \%$ & 383780 & $34.67 \%$ \\
\hline Fuel Consumption & 237787 & 136244 & $42.70 \%$ & 103726 & $56.38 \%$ & 108941 & $54.17 \%$ \\
\hline Thrust & 80726 & 59093 & $26.80 \%$ & 40012 & $50.43 \%$ & 50471 & $37.14 \%$ \\
\hline Average Improvement & $0.00 \%$ & \multicolumn{2}{|c|}{$32.86 \%$} & \multicolumn{2}{|c|}{$47.58 \%$} & \multicolumn{2}{|c|}{$42.00 \%$} \\
\hline Configuration & Baseline & \multicolumn{2}{|c|}{ C-Wing } & Extruded Wing & \multicolumn{2}{|c|}{ TBW } \\
\hline Gross Weight & 587419 & 389346 & $33.72 \%$ & 357282 & $39.18 \%$ & 344650 & $41.33 \%$ \\
\hline Fuel Consumption & 237787 & 115525 & $51.42 \%$ & 104611 & $56.01 \%$ & 80126 & $66.30 \%$ \\
\hline Thrust & 80726 & 49818 & $38.29 \%$ & 46629 & $42.24 \%$ & 50043 & $38.01 \%$ \\
\hline Average Improvement & $0.00 \%$ & \multicolumn{2}{|c|}{$41.14 \%$} & \multicolumn{2}{|c|}{$45.81 \%$} & $48.55 \%$ \\
\hline
\end{tabular}

\section{Analysis Methodology}

\section{A. FLOPS}

Meeting the Environmentally Responsible Aviation (ERA) project goals required an integrated, systems level design approach. The primary analysis and optimization tool used for this project was the FLOPS, a FORTRANbased code, developed at LaRC. This tool was originally intended to provide a low-fidelity analysis of CTW preliminary design concepts, and was ideally suited to the optimization of the CTW baseline model. It was, however, pushed to its limits during analysis of some of the unconventional concepts.

All of the design concepts and potential technologies for this project were analyzed using FLOPS because of its relative simplicity and reliability. FLOPS incorporates all areas of the design process, which expedites the conceptual design phase of a project by allowing multiple designs to be analyzed quickly through simple variable changes rather than an entire series of calculations. The user interacts with FLOPS by creating or editing a text file containing a list of variables organized into name lists for easy identification. Only lists of variables are required to run FLOPS in its most basic form, but name lists and variables can be added to the file to add analyses to the program. A manual is included with the program, which contains detailed information on necessary pieces of the program and explanations of each variable.

FLOPS contains variables that allow the user to set all of the mission profile requirements and design restrictions of an aircraft design, as well as more specific variables to input particular design element costs and benefits. As long as the immediate effects of a specific technology or airframe element are known, its overall effect on the aircraft system and mission impact can be easily determined.

FLOPS is distributed as FORTRAN code and must be compiled by the user. Because different systems compile code with slight variations, inconsistencies between the program's output on different computers and operating systems can occur, undermining the validity of results. Specifically, the program should be compiled with a g95 compiler, since the make file is written to use g95. The only way to ensure that the program has been compiled correctly is to compare the user outputs to the included example outputs. Distribution of a pre-compiled version, rather than as FORTRAN code, could eliminate these problems and the requirement for a FORTRAN compiler.

\section{B. Vehicle Sketch Pad}

Vehicle Sketch Pad (VSP) played a critical role in the configuration generation stage of the project. VSP is essentially a simplified computer aided drafting (CAD) program with modules specifically for creating aircraft concepts. Team members used VSP to generate 3D models of aircraft configurations. In addition, VSP contains a vortex lattice flow analyzer (VORVIEW) which was used in determining concepts' aerodynamic centers, as well as demonstrating the advanced concepts improved aerodynamic efficiency over CTW designs. The models helped clarify the advantages and drawbacks associated with each concept and aided in determining how new technologies, such as embedded engines or noise shielding, could be integrated into certain concepts. VSP was also used to demonstrate methods for stabilizing each generated concept, such as determining the location of the wing for proper static margin on a TBW concept. 


\section{Final Concepts}

\section{A. Concept Benefits and Costs}

\section{1. $T B W$}

The advanced tube and wing configuration was considered because of the ease of implementation into current airport and air traffic management infrastructure and manufacturing processes, although folding wings will be required in order to achieve this intergration. The TBW was chosen because it achieves a reduction of induced drag with a large aspect ratio wing. However, such a wing is easily susceptible to aeroelastic effects such as flutter or divergence. Rather than stiffening the wing by adding internal structure, a truss or strut can be implemented, reducing overall wing weight. Drawbacks include the additional weight and drag of the truss. The final design has an aspect ratio of 27 , requiring foldable wings to fit into existing airports. Two GTFs were placed underneath the wings and encased by the truss allowing for maximum noise shielding.

\section{2. $H W B$}

The HWB was selected due to the $12.8 \%$ reduction in fuel burn over traditional tube and wing ${ }^{19}$ from the reduced wetted area of $33 \%$ and reduced weight from the composite fuselage. By top mounting the engines, noise can be reduced and BLI incorporated to increase fuel efficiency. Wing bending stress is reduced due to wing thickness.

\section{Multiple Fuselage}

The multiple fuselage design was chosen because it may show span-wise distributed load benefits, similar to the HWB design while providing greater production simplicity due to its similarity to CTW aircraft. The load was distributed to make the weight distribution on the wings more similar to the designed span-wise wing loading. The team was concerned initially with the increase of parasitic drag due to increased surface area, but it was negligible in the final analysis. Analysis of this concept was accomplished by modifying the baseline configuration to have three fuselages, each approximately one-third the size of the original fuselage.

\section{B. Optimization}

Concept optimization was accomplished using FLOPS's optimization toolset. This toolset allows the user to choose from six different algorithms, twelve objective weighting factors, nineteen constraints, and seven design variables. The Broyden-Fletcher-Goldfarb-Shano (BFGS) Algorithm was utilized in this project. The minimized objective function weights chosen were direct operating cost and gross weight. These were selected to minimize the total required fuel and cost. The available design variables in FLOPS are gross weight, aspect ratio, thrust, wing area, taper ratio, sweep, thickness-to-chord ratio, cruise Mach number, and cruise altitude. Some of these parameters were used in the optimization of the final concepts. The constraints utilized in our analysis were on approach speed, field lengths, missed approach climb gradient thrust, second segment climb gradient thrust, and excess fuel capacity, which were the default constraints used in the baseline and maintained throughout the study.

\section{Design Specifications and Sizing}

Wing loading and thrust to weight ratio plots were constructed (See Figures 3, 4, \& 5) in order to provide an initial sizing estimate. Wing loading plots allow one to easily check the feasibility of a design with respect to important constraints such as balanced field length, cruise requirement, and the one engine out requirement ${ }^{20}$. The selected design points were chosen following optimization with FLOPS, which compared the design to the Federal Aviation Regulation (FAR) 25 for requirement compliance during concept optimization. Final design specifications are shown in 
Table 5 .

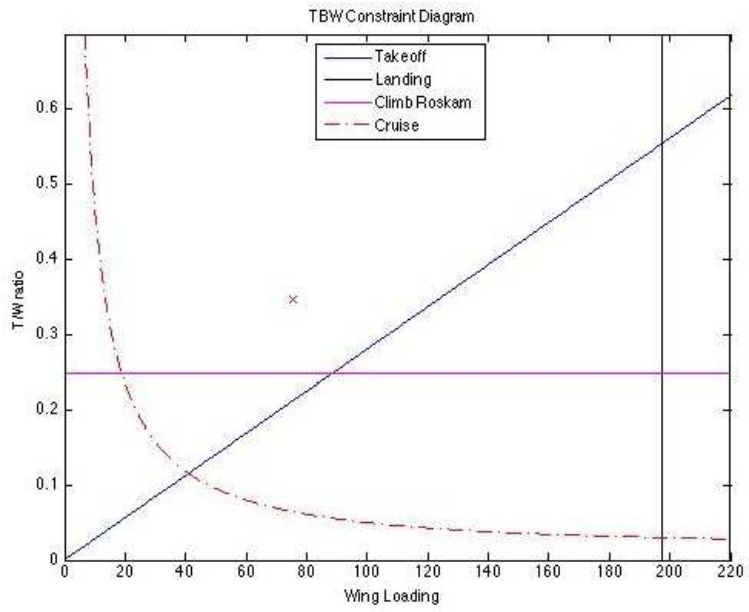

Figure 3. TBW Wing Loading

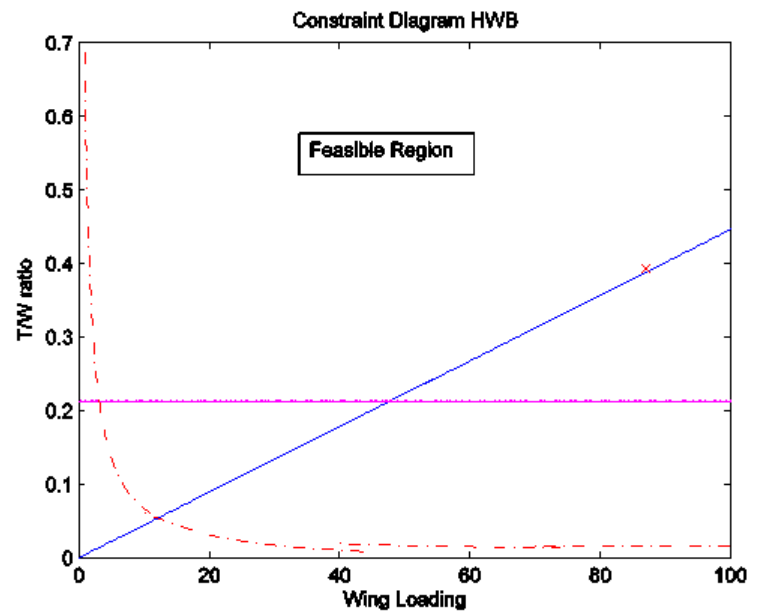

Figure 4. HWB Wing Loading

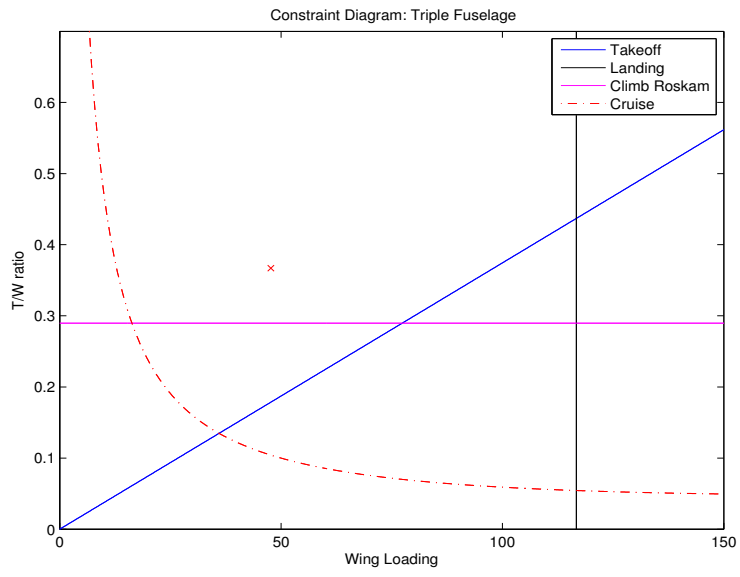

Figure 5. Multiple Fuselage Wing Loading

10

American Institute of Aeronautics and Astronautics 
Table 5. Final Design Specifications for TBW, HWB, and Multiple Fuselage Concepts

\begin{tabular}{|c|c|c|c|}
\hline Characteristic & TBW & HWB & MultiFuse \\
\hline Takeoff Weight (lb) & 460055 & 349765 & 381956 \\
\hline Empty Weight (lb) & 243144 & 156603 & 178542 \\
\hline Payload (lb) & 100000 & 100000 & 100000 \\
\hline Thrust-to-Weight Ratio & 0.347 & 0.392 & 0.367 \\
\hline Wing Loading (lb/sq ft) & 75.60 & 87.00 & 47.74 \\
\hline Thrust (lb) & 50043 & 40012 & 50741 \\
\hline SFc (1/hr) & 0.62 & 0.45 & 0.42 \\
\hline Fuel Burn (lb) & 116911 & 93162 & 103414 \\
\hline Span (ft) & 402 & 218 & 236 \\
\hline Reference Area (sq ft) & 6086 & 4018 & 8000 \\
\hline Aspect Ratio & 27 & 9 & 7 \\
\hline
\end{tabular}

\section{Weights and CG}

A weight buildup was conducted on a component level to ensure a stable and feasible craft. Each component was summed based on its aircraft location and weight to determine the center of gravity. Using VSP, the aerodynamic center of the aircraft was determined, after which the static margin was calculated. The three concepts shown in Table 6 have reasonable static margins, allowing for stable, yet responsive, flight.

Table 6. Component Weight Breakdown for TBW, HWB and Multiple Fuselage Concepts

\begin{tabular}{|c|c|c|c|c|c|c|}
\hline Aircraft & \multicolumn{2}{|c|}{ TBW } & \multicolumn{2}{c|}{ HWB } & \multicolumn{2}{c|}{ MultiFuse } \\
\hline Component & $\begin{array}{c}\text { Weight } \\
(\mathrm{lb})\end{array}$ & $\begin{array}{c}\text { X-cg Location } \\
(\mathrm{ft})\end{array}$ & $\begin{array}{c}\text { Weight } \\
(\mathrm{lb})\end{array}$ & $\begin{array}{c}\text { X-cg Location } \\
(\mathrm{ft})\end{array}$ & $\begin{array}{c}\text { Weight } \\
(\mathrm{lb})\end{array}$ & $\begin{array}{c}\text { X-cg Location } \\
(\mathrm{ft})\end{array}$ \\
\hline Wing & 103911 & 72.22 & 22088 & 41.92 & 44015 & 47.28 \\
\hline H-Tail & 3473 & 143.28 & 0 & 0.00 & 10025 & 59.11 \\
\hline V-Tail & 2664 & 135.32 & 2243 & 62.88 & 5226 & 59.11 \\
\hline Fuselage & 40125 & 74.32 & 43038 & 33.33 & 27081 & 56.15 \\
\hline Landing Gear & 18005 & 57.31 & 13633 & 45.00 & 15232 & 61.15 \\
\hline Engines & 22008 & 72.22 & 34358 & 52.88 & 21402 & 65.02 \\
\hline Fuel System & 1241 & 77.00 & 1728 & 32.56 & 2841 & 56.15 \\
\hline Controls & 6110 & 90.10 & 3968 & 43.92 & 6843 & 64.11 \\
\hline APU & 573 & 151.24 & 583 & 37.03 & 596 & 70.93 \\
\hline Instrumentation & 669 & 7.96 & 691 & 14.81 & 606 & 21.28 \\
\hline Hydraulics & 2432 & 66.22 & 2400 & 62.95 & 2652 & 59.11 \\
\hline Electrical & 1817 & 66.22 & 1905 & 22.22 & 1516 & 62.83 \\
\hline Avionics & 1824 & 12.74 & 1150 & 37.03 & 1189 & 11.82 \\
\hline A/C & 1858 & 71.64 & 5827 & 29.62 & 1705 & 42.56 \\
\hline Anti-Icing & 530 & 74.18 & 431 & 45.92 & 372 & 63.83 \\
\hline Pilot & 450 & 15.92 & 225 & 6.67 & 225 & 8.51 \\
\hline Unusable Fuel & 812 & 77.00 & 900 & 32.56 & 1029 & 56.15 \\
\hline Oil & 252 & 72.22 & 263 & 52.88 & 231 & 65.02 \\
\hline Cargo Containers & 18550 & 74.82 & 18550 & 18.52 & 18550 & 56.15 \\
\hline Cargo & 100000 & 74.82 & 100000 & 18.52 & 100000 & 56.15 \\
\hline Fuel & 116912 & 73.52 & 93162 & 32.56 & 104244 & 56.15 \\
\hline Center of Gravity & 444206 & 73.52 & 347143 & 31.29 & 366890 & 55.18 \\
\hline Aerodynamic & & 74.11 & & 34.03 & & 58.17 \\
\hline Center & & & & $5.45 \%$ & & $5.32 \%$ \\
\hline Static Margin & & $5.10 \%$ & & & \\
\hline
\end{tabular}


American Institute of Aeronautics and Astronautics 


\section{E. Use of Advanced Technologies \\ 1. $T B W$}

Up to $70 \%$ of the structure is made of composites to increase structural efficiency and reduce weight. The fuselage can be constructed in one piece with an OOA process, eliminating many fasteners, saving manufacturing time, cost, and weight. The use of two GTF engines reduces fuel burn and noise while increasing propulsive efficiency. The engines are equipped with chevrons for additional noise reduction, advanced combustors to reduce LTO $\mathrm{NO}_{\mathrm{X}}$ and drop-in bio-fuels to reduce well-to-wake $\mathrm{CO}_{2}$ emissions. The truss is optimized to maximize noise shielding. Riblets are infused into the fuselage paint to reduce turbulent skin friction drag.

\section{2. $H W B$}

GTF engines are used to reduce fuel consumption and $\mathrm{LTO} \mathrm{NO}_{\mathrm{X}}$. The application of BLI further increases aerodynamic efficiency by reducing overall drag. PRSEUS advanced composite material allows for pressure containment without a significant weight penalty. Active chevrons reduce engine noise by $9 \mathrm{~dB}$ and remove the fuel burn penalty seen in passive chevrons. Solid oxide fuel cells offers savings as it increases the Auxiliary Power Unit (APU) efficiency. The riblets on the fuselage portion and HLFC on the outboard wings decrease drag.

\section{Multiple Fuselage}

Aerodynamically, the multiple fuselage design reduces drag through the use of riblets, hybrid laminar flow control, and wingtip devices. Two GTF engines are mounted within the empennage to reduce emissions and noise; the empennage is used for extra noise shielding. Chevrons on the exhaust nozzles help reduce engine noise. To create a design with the lightest possible weight, composite materials were used wherever possible.

\section{F. Concept Emissions}

Configuration-specific LTO $\mathrm{NO}_{\mathrm{X}}$ was estimated using FLOPS, without taking into account advances in engine combustor technology. Because it was not feasible to predict actual $\mathrm{NO}_{\mathrm{X}}$ emissions using FLOPS, the data was used to determine the comparative $\mathrm{NO}_{\mathrm{X}}$ emissions of each aircraft concept. However, current combustor technology enables at least a $50 \%$ reduction in $\mathrm{NO}_{\mathrm{x}}$ emissions below the CAEP/6 standard. Further reductions are likely within the $\mathrm{N}+2$ timeframe and may enable the ERA goal of $75 \%$ below CAEP/6.

\section{1. $T B W$}

The fuel burn was reduced by $37 \%$ and $\mathrm{LTO} \mathrm{NO}_{\mathrm{X}}$ by $50 \%$ in accordance with current technology but did not provide any additional configuration dependent LTO NOx reduction.

\section{2. $H W B$}

Proportional reductions in $\mathrm{NO}_{\mathrm{X}}$ emissions for each of the advanced configurations can be assumed since thrustspecific $\mathrm{NO}_{\mathrm{X}}$ emissions are independent of aircraft configuration. Configuration relative $\mathrm{NO}_{\mathrm{X}}$ emissions were determined and are shown in Figure 6. The HWB is the lowest, but paradoxically the least compliant with CAEP/6. This occurs, because the CAEP/6 standard is thrust specific, and the HWB has the lowest thrust, yet produces almost as much $\mathrm{NO}_{\mathrm{X}}$ as the higher thrust multiple fuselage design. The differences in $\mathrm{NO}_{\mathrm{X}}$ are due to differences in required thrust and time during takeoff, climb, and descent.

\section{Multiple Fuselage}

The multiple fuselage concept showed $\mathrm{NO}_{\mathrm{X}}$ emissions intermediate to those of the TBW and HWB.

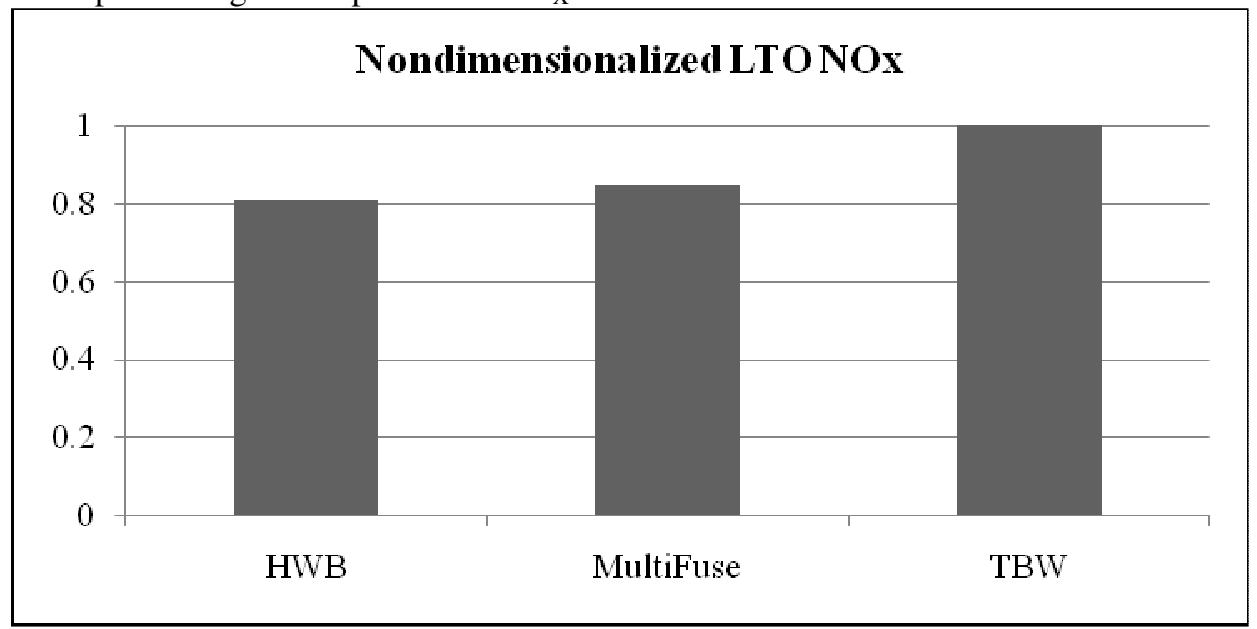

American Institute of Aeronautics and Astronautics 


\section{Figure 6. TBW, HWB, and Multiple Fuselage Concept $\mathrm{NO}_{\mathrm{x}}$ Comparison}

\section{G. Concept Fuel Burn}

1. $T B W$

Fuel burn goals were defined by the total amount of required fuel calculated in FLOPS to complete the $6500 \mathrm{nmi}$ mission. All of the $\mathrm{N}+2$ technologies incorporated into this concept improved fuel burn. Figure 7 shows how each technology impacted the gross weight and fuel burn. The percent changes are based on the 767 baseline. The technologies were independently incorporated into the TBW to analyze their individual benefit.

Viscous drag was reduced by $7 \%$ through the use of advanced aerodynamic technologies. Specific fuel consumption was reduced $14.3 \%$ through the use of advanced propulsion technologies, and composite utilization was increased to $100 \%$ with advanced structural technology. Surprisingly, propulsion technology when applied alone increased the gross weight and fuel burn significantly, while the TBW configuration alone caused an increase in weight but a large decrease in fuel burn.

\section{2. $H W B$}

The fuel burn for the $6500 \mathrm{nmi}$ mission was 93162 pounds. This was an improvement of 94659 pounds or $50.4 \%$ over the baseline configuration. Figure 7 shows how improvements in the different disciplines affected the fuel savings. The configuration change from conventional tube and wing to HWB with composite material resulted in $23.8 \%$ fuel savings. The addition of GTF utilizing BLI resulted in additional savings of $16 \%$. HLFC and riblets added $10.5 \%$ efficiency. The results show that much can be gained by moving away from the conventional configuration and conducting further research in this area.

\section{Multiple Fuselage}

The multiple fuselage design did not achieve the N+2 ERA fuel burn goals. However, through the use of an advanced conceptual configuration and advanced technologies, this design was shown to achieve a $45 \%$ reduction in fuel burn on the baseline while reducing the operating cost nearly $29 \%$ from the baseline.

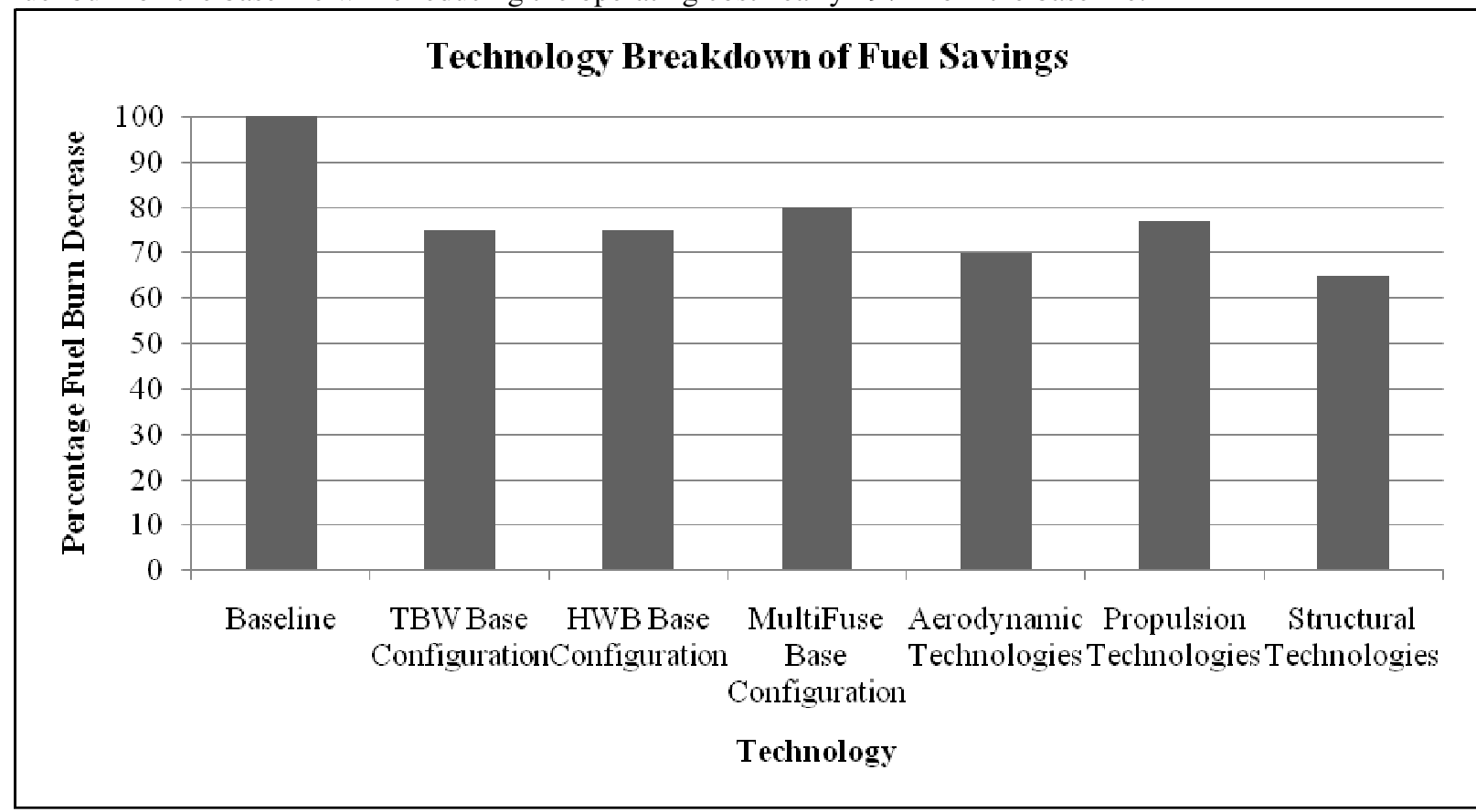

Figure 7. Technology Breakdown of Fuel Savings

\section{H. Concept Noise}

All of the concepts incorporate active chevrons to aid in reducing noise.

\section{1. $T B W$}

The TBW incorporates engine shielding and advanced propulsion technology to aid in noise reductions. The engines are placed so that the truss provides noise shielding. Passive and active chevrons were placed on the nacelles and nozzles; it was assumed based on the FLOPS results that passive chevrons would reduce noise by $3 \mathrm{~dB}$.

Advanced GTF engines were used in the analysis of the TBW in order to reduce noise by an additional $10 \mathrm{~dB}$. A contour plot of the effective perceived noise level (EPNL), better known a noise tadpole, is shown in Figure 9. 
Comparing the baseline (See Figure 8) and TBW concept tadpoles shows the significant reductions in noise. This concept meets the ERA requirements with a reduction below the stage 4 requirements, which will allows the TBW to access a wider range of airports and flight schedules and lead to reduced costs for cargo operators.

\section{2. $H W B$}

The HWB showed a reduction in noise through the use of shielding and chevrons. Placing the engines above the wing and between vertical stabilizers, shields the engine noise. The HWB uses advanced active chevrons, which reduce the output noise by approximately $9 \mathrm{~dB}$. The engine technology in the GTF reduces the noise in each flight section by $10 \mathrm{~dB}$, resulting in an overall $30 \mathrm{~dB}$ reduction.

The HWB showed a reduction of $37 \mathrm{~dB}$ past stage four, which provides a more community friendly takeoff (See Figure 10). The GTF had the greatest impact, followed by the chevrons and the shielding. The overall reduction was $37 \mathrm{~dB}$, which does not meet the $\mathrm{N}+2$ goal of $42 \mathrm{~dB}$ reduction.

\section{Multiple Fuselage}

The multiple fuselage design achieved the N+2 ERA goals within 20\%. Through analysis in FLOPS, this design shows a $44 \mathrm{~dB}$ noise reduction below stage 4 requirements. By achieving a $44 \mathrm{~dB}$ noise reduction from stage 4 , the multiple fuselage design was the only configuration to meet the ERA noise requirement. As shown in the noise tadpole of the multiple fuselage in Figure 11, the multiple fuselage reduces EPNL significantly compared to the baseline.

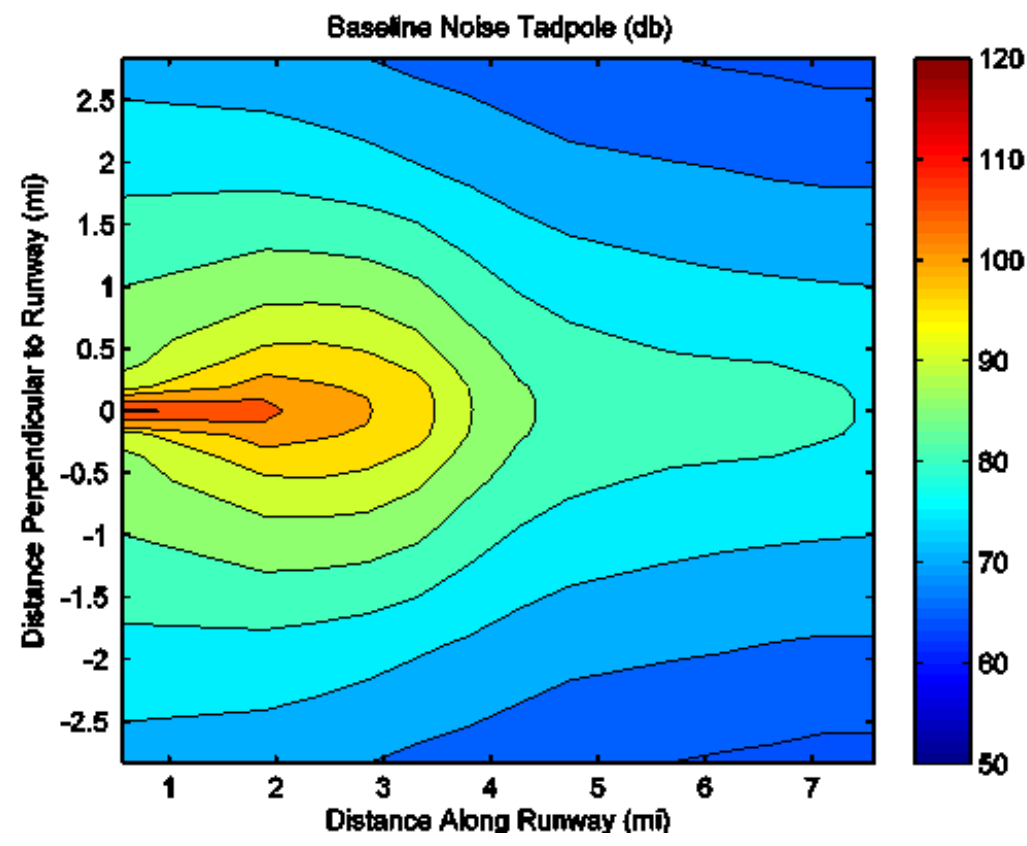

Figure 8. Noise Tadpole for Baseline Configuration 


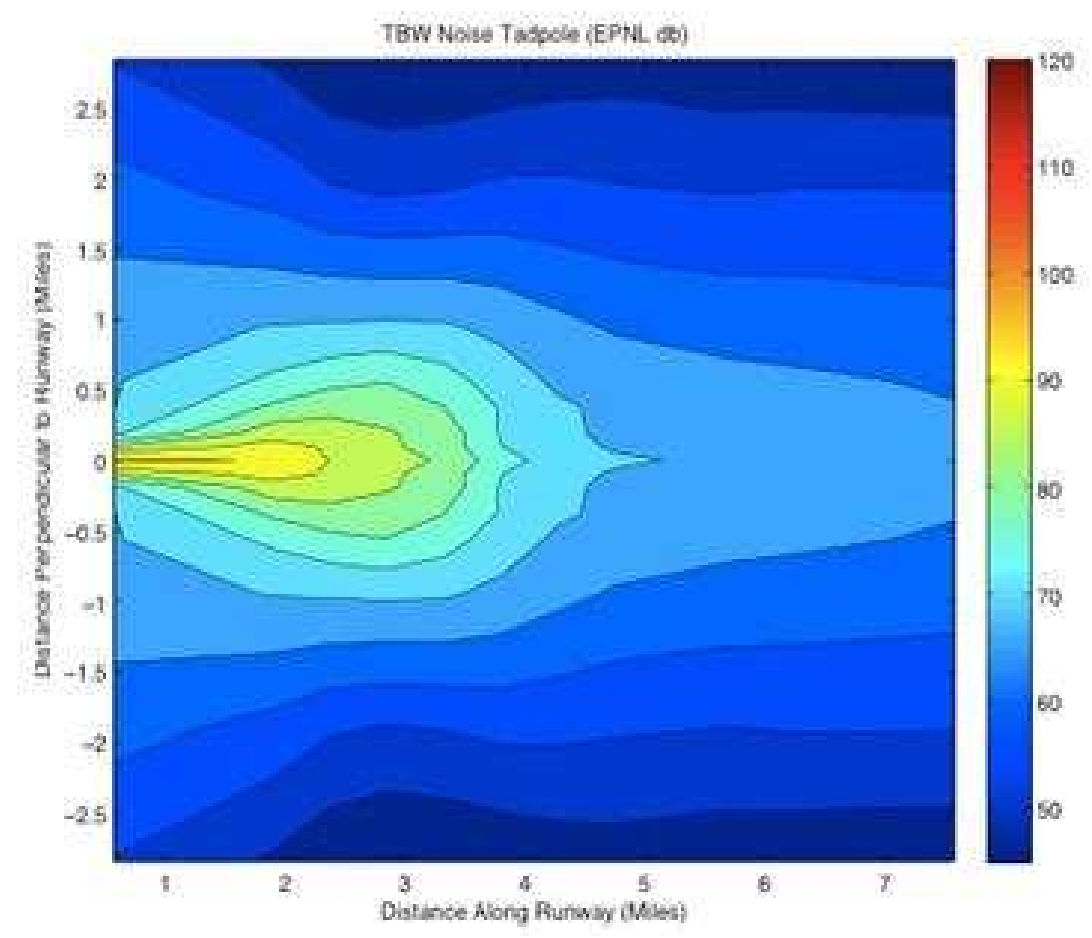

Figure 9. Noise Tadpole for TBW Concept

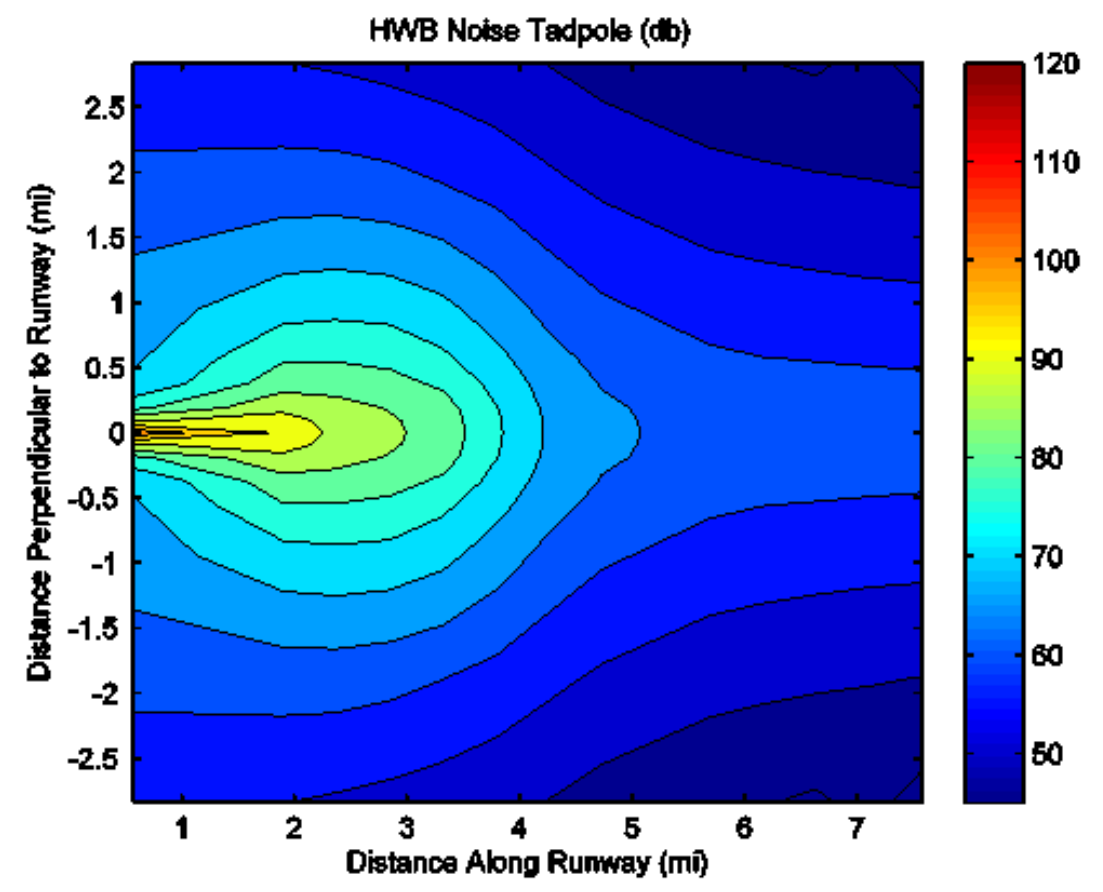

Figure 10. Noise Tadpole for HWB Concept 


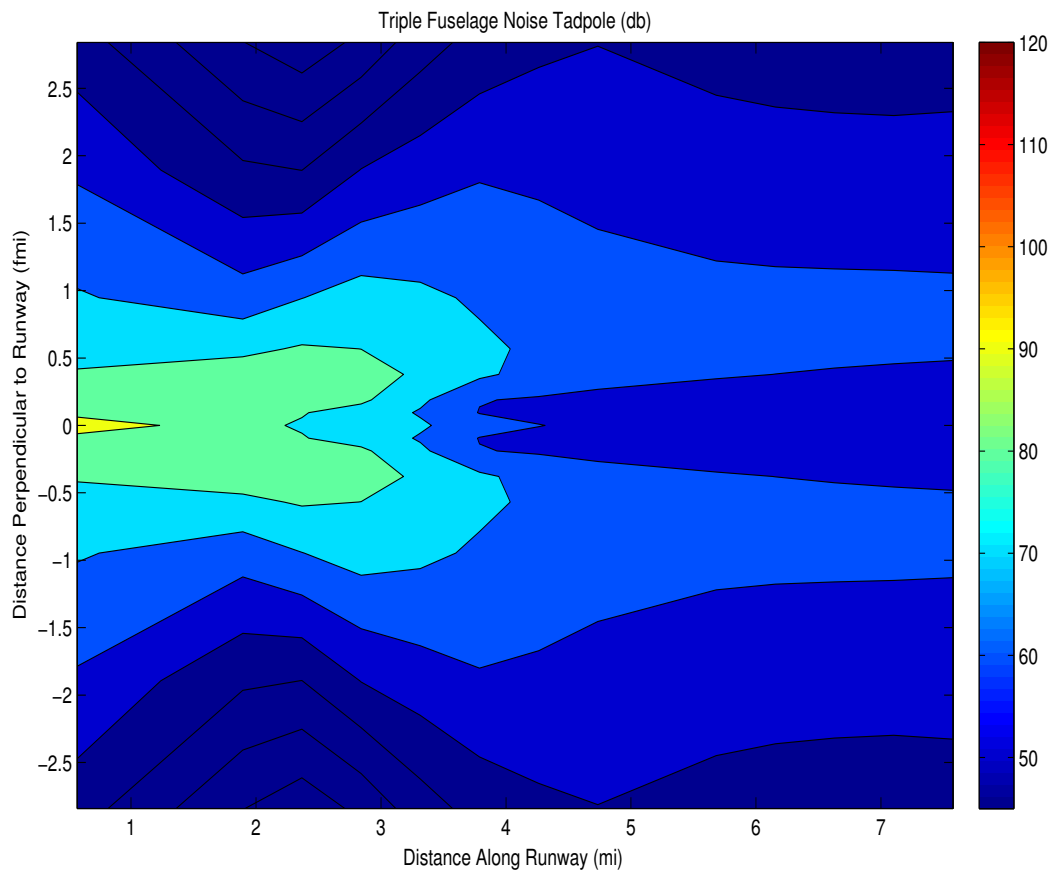

Figure 11. Noise Tadpole for Multiple Fuselage Concept

\section{Results}

None of the three designs accomplished all of the $\mathrm{N}+2$ goals, yet they all performed well and improved in the ERA goal areas, as shown in Table 7.

Table 7. Results

\begin{tabular}{|c|c|c|c|c|c|}
\hline Configuration & Goal & Baseline & TBW & HWB & MultiFuse \\
\hline Fuel Burn Reduction (\%) & $-50.00 \%$ & $0.00 \%$ & $-36.90 \%$ & $50.50 \%$ & $-44.90 \%$ \\
\hline Noise Below Stage 4 (dB) & -42.00 & 4.20 & -35.50 & -37.30 & -40.10 \\
\hline NOx Below CAEP/6 & $-70.00 \%$ & $0.00 \%$ & $-50.00 \%$ & $-50.00 \%$ & $-50.00 \%$ \\
\hline
\end{tabular}

In terms of fuel burn, the HWB has the best performance. When noise is considered, the multiple fuselage clearly prevails. The multiple fuselage's shielding is distinguished from the others in the acoustic considerations. All configurations assumed the same combustor technologies, which resulted in the same $50 \%$ reduction in $\mathrm{NO}_{\mathrm{X}}$ for all three designs based on the CAEP/6 requirement. Overall, the HWB and multiple fuselage designs display the best results for the ERA goals. The multiple fuselage is the ideal design for noise mitigation while the HWB is the ideal design for fuel burn reduction.

\section{Future Work}

The HWB and the multiple fuselage are recommended for further in-depth study. Significant research has already been conducted on the HWB, so further study may be less challenging than that of the multiple fuselage design. As the fuselages are span loaded in the multiple fuselage configuration, a detailed structural analysis will be required. Since this study was performed with FLOPS, a higher fidelity structural analysis should be performed to fully quantify any benefits to weight reduction seen during the conceptual design phase.

The benefits of the UAS systems will need to be studied further as well. This includes the development of a weight saving fully unmanned platform; items such as windows can be neglected and the structure required to hold them in place can be removed, greatly reducing the weight of the airframe.

Additionally, folding wings will need to be investigated further, as the span on the TBW craft is over 400 feet. 


\section{Acknowledgments}

The authors would like to thank Dr. Fayette Collier, Mr. William Kimmel, and Dr. Elizabeth Ward for all of their guidance and help throughout this project. The authors would also like to thank all of the subject matter experts from NASA LaRC and NASA GRC for help throughout this project.

\section{References}

${ }^{1}$ Tracy, J. J., "Future Aviation Developments: A Boeing Perspective" The Boeing Company, 2011, [http://www.cdti.es/recursos/doc/eventosCDTI/Aerodays2011/PS32.pdf. Accessed 8/1/11.]

${ }^{2}$ Collier, F. S., "Overview of NASA's Environmentally Responsible Aviation (ERA) Project," NASA ERA Project, 2010, [http://www.aeronautics.nasa.gov/pdf/asm_2010_collier_508.pdf Accessed 8/1/11.]

${ }^{3}$ Warwick, G., "Riblets Back in the Groove," Leading Edge, Aviation Week and Space Technologies, June 2010.

[http://www.aviationweek.com/aw/blogs/aviation_week/on_space_and_technology/index.jsp?

plckController=Blog\&plckBlogPage=BlogViewPost \&newspaperUserId=a68cb417-3364-4fbf-a9dd-

4feda680ec9c\&plckPostId=Blog\%3aa68cb417-3364-4fbf-a9dd-4feda680ec9cPost\%3ab5065dcb-10d0-447c-9b85-

cf91c64363f1\&plckScript=blogScript\&plckElementId=blogDest. Accessed 6/25/11.]

${ }^{4}$ Lange, R. H., "Design Integration of Laminar Flow Control for Transport Aircraft," Journal of Aircraft, Vol. 21, No. 8, 1984, pp. 612-617.

${ }^{5}$ Allmon, B. “CLEEN Consortium Open Session,” GE Aviation, October 2010.

[http://www.faa.gov/about/office_org/headquarters_offices/apl/research/aircraft_technology/cleen/2010_consortium/media/GE\%

20-\%20FAA\%20CLEEN\%20Consortium\%202010\%20-\%20Unlimited\%20Rights.pdf. Accessed 6/22/11.]

6 "Summary of Wind Tunnel Tests and Vehicle Analysis for Open Rotor Propulsion Systems," Presentation to ICAO's Noise Technology Independent Expert Panel, National Aeronautics and Space Administration, 2012.

${ }^{7}$ Sweetman, B., "The Short, Happy Life of the Propfan," Airspacemag, September 2005,

[http://www.airspacemag.com/history-of-flight/prop-fan.html. Accessed 3/29/12.]

${ }^{8}$ Schweitzer, J. K., Anderson, J. S., and et. al, "Validation of Propulsion Technologies and New Engine Concepts in a Joint Technology Demonstrator Program,” XVII ICAS, 2006.

${ }^{9}$ Abrams, M. "Put a Nozzle on It," Mechanical Engineering, November 2006.

[http://memagazine.asme.org/articles/2006/november/Put_Nozzle.cfm. Accessed 6/20/11.]

${ }^{10}$ Kawai, R.T., Friedman, D.M., and Serrano, L. "Blended Wing Body (BWB) Boundary Layer Ingestion (BLI) Inlet Configuration and System Studies,” NASA CR-2006-214534, December 2006.

${ }^{11}$ Plas, A.P., Sargeant, M.A., Crichton, D., Greitzer, E.M., Hynes, T.P., and Hall, C.A. "Performance of a Boundary Layer Ingesting (BLI) Propulsion System.” AIAA Paper 2007-450, January 2007.

${ }^{12}$ Owens, L.R., Allan, B.G., and Gorton, S.A., "Boundary-Layer-Ingesting Inlet Flow Control," AIAA Journal of Aircraft, Vol. 45, No. 4, 2008, pp. 1431-1440.

${ }^{13}$ Kinder, J.D., and Rahmnes, T., "Evaluation of Bio-Derived Synthetic Paraffinic Kerosene (Bio-SPK)," Paris Air Show, The Boeing Company, June 2009.

${ }^{14}$ Hileman, J.I., Ortiz, D.S., Bartis, J.T., Wong, H.M., Donohoo, P.E., Weiss, M.A., and Waitz, I.A., "Near-Term Feasibility of Alternative Jet Fuels," RAND Corporation, COE-2009-001, Santa Monica, CA, 2009.

${ }^{15}$ Airforce-technology, "Advanced Composite Cargo Aircraft (ACCA)" Airforce-Technology, 2007, [http://www.airforcetechnology.com/projects/composite-cargo/. Accessed 8/2/11.]

${ }^{16}$ Rhodes, J. R., "Transformer: Rise of the Composites" Code One Lockheed Martin, 2010,

[http://www.codeonemagazine.com/article.html?item_id=20. Accessed 8/2/11.]

${ }^{17}$ Soban, D.S., Upton, E., "Design of a UAV to Optimize Use of Fuel Cell Propulsion Technology", AIAA Paper 2005-7135, Sept, 2005.

${ }^{18}$ Kernstine, K., Boling, B., Bortner, L., Hendricks, E., Mavris, D., "Designing for a Green Future: A Unified Aircraft Design Methodology", Journal of Aircraft, Vol. 47, No. 5, 2010 pp. 1789-1797.

${ }^{19}$ Nickol, C. L., McCullers, L. A., "Hybrid Wing Body Configuration System Studies”, AIAA Paper 2009-0931, Jan. 2009.

${ }^{20}$ Raymer, D. P., “Aircraft Design: A Conceptual Approach”, 4th ed., 2006, Reston, Virginia, AIAA 